\title{
Shape Design and Experiment Research of the Supercavitat- ing Underwater High-Speed Projectile
}

\author{
W. J. Ying*, J. Hou, P. Wei \\ Department of Weapon Engineering, Naval University of Engineering, Wuhan 430033, China \\ Email: yingwenjian@sohu.com
}

\begin{abstract}
Recently experiments have shown that supercavity can be produced by a high-speed projectile underwater. By using this effect, we may render underwater projectile run very fast with high stability if it can be under effective control.

However, the underwater environment is always very complicated. Therefore, all factors should be integratedly considered in order to design a weapon of long range and with strong power.

The article presents methods and gist for the design of this kind of underwater projectiles. The model is based on the potential panel method for slender axisymmetric bodies. When Hess-Smith method is adopted, an equation for resources distributing way on the body surface is given. Then, the disturbed potential and velocity can be calculated along with the shape of supercavity.

The effects of various factors are further analyzed. Finally, the comparison between calculation and experiments verifies the creditability and feasibility of the methods.
\end{abstract}

\section{REFERENCES}

1. Savchenko. Supercavitation-problems and perspective. In: Forth International Symposium on Cavitation. Passbena: California Institute of Technology, 2001

2. Savchenko. Investigation of High-speed supercavitating underwater motion of bodies. In: Proc AGARD FDP Workshop on High Speed Motion in Water, Kiev, Ukraine, 1997, 194-205

3. Fine N E, Kinnas S A. A boundary element method for the analysis of the flow around 3-D cavitating hydrofoils. J Ship Res, 1993; 37(3): 213-224

4. Fu H P, Li F X. A numerical analysis of the flow around a partially-cavitating axisymmetric body. Acta Mechanica Sinica, 2002; 34(2): 278-284

5. Cheng X J, Lu C J. On the partially cavitating flow around two-dimensional hydrofoils. Applied Mathematics and Mechanics, 2000; 21(12): 1310-1317 